\title{
THE GROWTH-RATE OF JUVENILE ASTERIAS RUBENS L.
}

\author{
By H. Barnes and H. T. Powell \\ The Marine Station, Millport
}

(Text-fig. I)

The general biology of the common starfish, Asterias rubens L., has recently been studied by Vevers (1949), whose investigations included observations on the growth-rate of this species. His material was collected in the Plymouth area largely by means of an otter trawl, supplemented by a few Agassiz and dredge hauls, and there are therefore few records in his data of the growth-rate of juvenile $A$. rubens under natural conditions. Vevers also made observations on the growth-rate of individuals kept in laboratory tanks, but again the results apply mainly to fairly large animals. The only other direct observations on growth-rate appear to be those of Bull (1934), who dealt with three small individuals kept in aquarium tanks, while Orton \& Fraser (1930) give measurements made on a natural population taken, after one year's growth, from a buoy.

While examining barnacle-covered panels, suspended $2 \mathrm{ft}$. below the surface from a raft moored at Millport, large numbers of very small (about $4.5 \mathrm{~mm}$. radius) $A$. rubens were noted during early August I950 and, in view of the lack of information on the growth-rate of such small starfish, samples of this population were collected and measured at intervals over a period of 6 months; the data so obtained supplement those given in the investigations referred to above.

The panels (each $15 \times$ IO in.) had only been exposed since March 1950 and by the beginning of August, when the collections of starfish were first made, were covered with close-packed elongated barnacles-mixed Balanus crenatus Brug. and B. balanoides (L.), similar to the growth described and figured by Barnes \& Powell (1950, P1. I)—-together with numerous young Mytilus edulis L. Although many of the barnacles had already been killed by the predatory activities of the nudibranch Onchidoris fusca (O. F. Müller), large numbers of which were present on the panels at this time, the panels would appear from the point of view of food supply to have been an ideal site for the growth of young starfish.

There were a number of such panels all carrying this young Asterias population, and each subsequent sample of the latter consisted of all the starfish that could be found on one or more of the densely colonized panels. No panel 
was sampled more than once, errors due to selection being thereby minimized. The animals were brought into the laboratory and killed in weak alcohol with the arms fully extended, and measured immediately. In view of the difficulty of determining the exact position of the anus in the smallest specimens, the distance from the centre of the disk to the tip of the longest ray was measured and this measurement was adhered to in all subsequent samples; a vernier measuring microscope was used for the smaller, and ordinary dividers for the larger animals. Table I gives the dates of collection, the numbers of starfish measured, the mean length (radius), the standard error of each mean, together with the increase in the mean length per 30 days. The mean lengths and the monthly mean surface sea-water temperatures near the site are plotted in Fig. I.

In the subsequent discussion of growth-rate our results can be considered comparable with those of Bull (I934), who gives the mean radius of all the arms of normal length of each individual measured from the centre of the disk, and with those of Vevers, although the latter author in accordance with general convention for adult asteroids, measured the distance from the anus to the tip of the longest arm. In considering the results of Orton \& Fraser (I930), the conversions made by Vevers are used.

It is well known that large starfish wander over considerable distances, and they may climb on to rafts and moored buoys via the mooring chains. It is considered that the population under consideration, which was under observation at frequent intervals (in addition to the occasions when the starfish samples were being taken) received no influx in this way. The possibility exists that some of the larger starfish may have dropped off the panels but this is considered unlikely, although late in the season there was some evidence that the larger starfish did move from panel to panel. It is almost certain that the young starfish had developed from larvae which settled directly on the panels since, according to Gemmill (I9I4), spawning of $A$. rubens takes place at Millport from April to June, varying somewhat from year to year, and development of the larva to the youngest adult form takes from 9 to ro weeks.

Irregularities in the growth-rate curves of $A$. rubens seem to be common, as is emphasized by Vevers in discussing his results; a similar irregularity is seen in our growth-curve which is that of mean sizes. However, there were two periods of uniform growth: in the first period ( 7 August 1950 to 5 October I950) the average of the separate estimates of the rate of increase of the mean size is $4.4 \mathrm{~mm}$. per 30 days, while in the second period (2 November I950 to 22 January I95I) the value is somewhat lower: $3.2 \mathrm{~mm}$. per 30 days (see Table I and Fig. I).

Vevers (I949, p. I72) points out that starfish up to at least $6 \mathrm{~cm}$. radius can grow at a monthly rate of rather more than $10 \mathrm{~mm}$. in the summer and rather less than $5 \mathrm{~mm}$. in winter. However, his two smallest animals, B8 and B9, 
show the variation in growth which can take place between individuals kept under apparently identical environmental conditions. Thus B 8 grew from I3 to $39 \mathrm{~mm}$. from 6 July to 2I September I947, that is an overall rate of $10 \mathrm{~mm}$.

\section{Table I. Analysis of Growth-Rate of Samples of Young ASTERIAS RUBENS}

Date of
collection
7 Aug. I950
I9 Aug. I950
30 Aug. I950
I6 Sept. I950
5 Oct. 1950
I8 Oct. I950
2 Nov. 1950
5 Dec. 1950
28 Dec. I950
22 Jan. I951

No. in
sample
33
31
48
38
50
71
75
73
68
78

Mean length $(r)$ of sample (mm.)

4.6
5.9
7.5
10.6
13.4
17.9
18.9
23.1
25.3
27.8

Increase in mean length $(r)$, mm. per 30 days

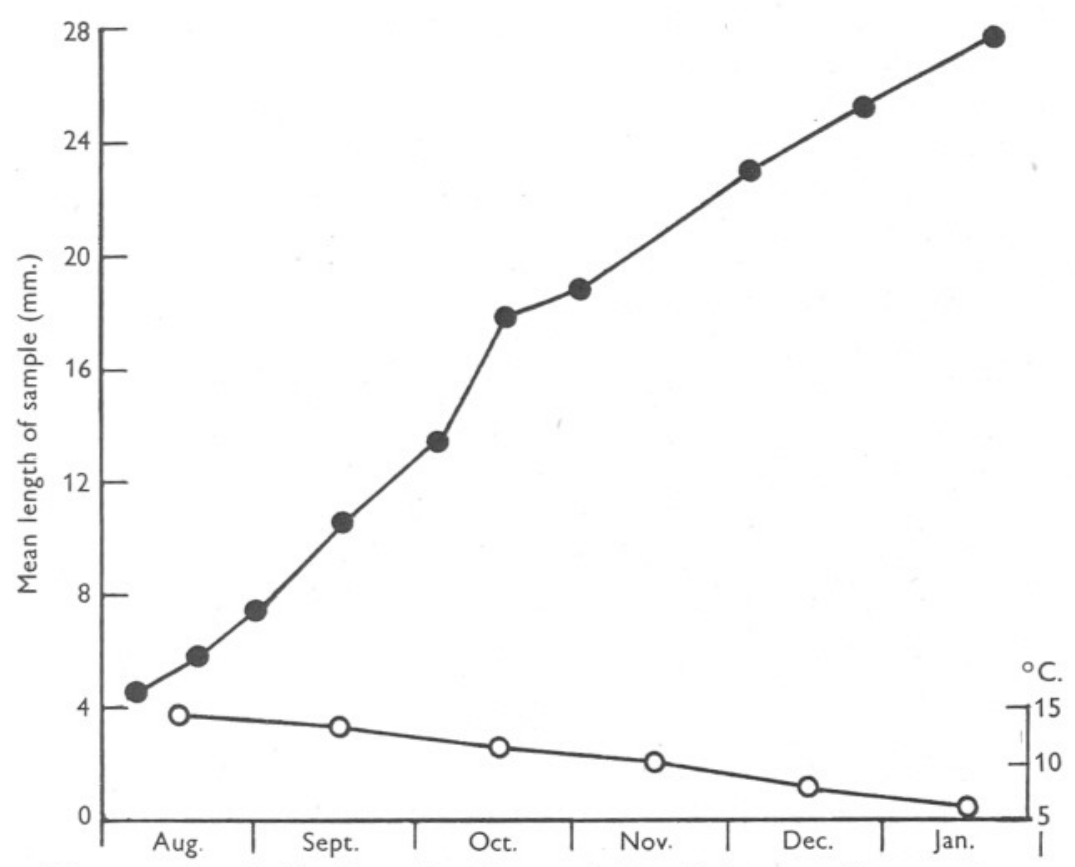

Fig. I. The mean length $(r)$ of samples of a population of Asterias rubens growing on raftexposed panels $(\bullet)$, together with the monthly mean surface sea-water temperatures near the site $(0)$.

per 30 days, and $\mathrm{B} 9$ increased from 10 to $27 \mathrm{~mm}$. during roughly the same period (20 July to 2I September I947), an overall rate of 8.I mm. per 30 days. The latter animal (B9) increased its overall rate to I I mm. per 30 days during the late autumn and winter (26 October to I4 December I947). 
The present results are for the means of a series of samples, and therefore supply no information regarding variation in growth-rate of individuals of the same age or size, but in view of the variations discussed above there would not seem to be any great discrepancy between our results and those of Vevers, although in general the latter are somewhat greater; indeed he estimated that the animals used in his experiments had grown at an average rate of $5 \mathrm{~mm}$. per month over the I2 months before capture.

The results are also in agreement with those of Bull (I934) for the growth of two of his animals, $2(b)$ and 3 , reared in the laboratory; these showed an overall growth rate of 3.3 and $6.0 \mathrm{~mm}$. per 30 days respectively during comparable periods of the summer and early autumn months (May to September I929).

Orton \& Fraser (I930) measured I805 small $A$. rubens taken from a buoy in Liverpool Bay, and estimated that the modal size attained by this population after I year's growth was $22 \mathrm{~mm}$., with a range from 6 to $52 \mathrm{~mm}$.; this corresponds to a monthly increment of approximately $2.5 \mathrm{~mm}$. around the mode (which was little different from the mean). The growth of this population, therefore, was much less than that observed either in the experimental animals of Bull and Vevers or in those of the present investigation.

Vevers's results have clearly shown the great effect of reduced food supply in lowering the growth-rate of animals of such voracious habits as A. rubens. Both his and Bull's animals were reared in laboratory tanks with a plentiful supply of the appropriate kind and size of food, and the present results show that a similar growth-rate can be attained under natural conditions. The discrepancy between these results and those of Orton \& Fraser would hardly seem to be due to a temperature effect, since the surface seawater temperatures at Millport (Fig. I) are very similar to those of Liverpool Bay (Proudman, Lewis \& Dennis, I937). It is considered that a shortage of food of the appropriate kind at some stage in their growth, rather than possible loss of some of the larger animals due to wind and wave action, is more likely to account for this discrepancy.

\section{SUMMARY}

A population of young Asterias rubens settled on raft-exposed panels has been sampled at frequent intervals over a period of 6 months.

The conditions under which this population developed are described, and from the measurements obtained estimates are given of the growth-rate during the period of the observations.

These values are compared with those obtained by other workers. 


\section{REFERENCES}

BARNes, H. \& Powell, H. T., I950. The development, general morphology and subsequent elimination of barnacle populations, Balanus crenatus and B.balanoides, after a heavy initial settlement. Fourn. Anim. Ecol., Vol. 19, pp. 175-9.

Bull, H. O., I934. Aquarium observations on the rate of growth and enemies of the common star-fish, Asterias rubens L. Report of the Dove Marine Laboratory, Third Series, No. 2, pp. 60-5.

Gemmill, J. F., I9I4. The development and certain points in the adult structure of the starfish Asterias rubens L. Phil. Trans. Roy. Soc., B, Vol. 205, pp. 213-94.

Orton, J. H. \& Fraser, J. H., I930. Rate of growth of the common starfish, Asterias rubens. Nature, Vol. I26, p. 567.

Proudman, J., Lewis, H. M. \& Dennis, A. L., I937. On the temperature of the surface waters of the Irish Sea. Phil. Trans. Roy. Soc., A, Vol. 236, pp. 26I-302.

VeVERS, H. G., I949. The biology of Asterias rubens L.: growth and reproduction. fourn. Mar. Biol. Assoc., Vol. xxvin, pp. 165-87. 